\title{
OVERALL PSD AND FRACTAL CHARACTERISTICS OF TIGHT OIL RESERVOIRS: A CASE STUDY OF LUCAOGOU FORMATION IN JUNGGAR BASIN, CHINA
}

\author{
XIXIN WANG,${ }^{*, \dagger}$ JIAGEN HOU $,{ }^{*}, \dagger, \|$ YUMING LIU, ${ }^{*, \dagger, * *}$ PEIQIANG ZHAO,${ }^{\ddagger}$ \\ KE MA,${ }^{*}$, DONGMEI WANG,${ }^{\S}$ XIAOXU REN ${ }^{*, \dagger}$ and LIN YAN $\uparrow$ \\ *State Key Laboratory of Petroleum Resource and Prospecting \\ China University of Petroleum, Beijing 102249, P. R. China \\ ${ }^{\dagger}$ College of Geosciences, China University of Petroleum-Beijing \\ Beijing 102249, P. R. China \\ ${ }^{\ddagger}$ Hubei Subsurface Multi-Scale Imaging Key Laboratory \\ Institute of Geophysics and Geomatics \\ China University of Geosciences \\ Wuhan 430074, P. R. China \\ $\S$ Harold Hamm School of Geology $\&$ Geological Engineering \\ University of North Dakota, GF 58202, USA \\ IPetroChina Research Institute of Petroleum \\ Exploration $\&$ Development, Beijing, P. R. China \\ \|jghou63@hotmail.com \\ **ymliu83@hotmail.com
}

Received January 9, 2018

Accepted January 31, 2018

Published August 29, 2018

\footnotetext{
"Corresponding author.
}

This is an Open Access article published by World Scientific Publishing Company. It is distributed under the terms of the Creative Commons Attribution 4.0 (CC-BY) License. Further distribution of this work is permitted, provided the original work is properly cited. 


\begin{abstract}
Lucaogou tight oil reservoir, located in the Junggar Basin, Northwest of China, is one of the typical tight oil reservoirs. Complex lithology leads to a wide pore size distribution (PSD), ranging from several nanometers to hundreds of micrometers. To better understand PSD and fractal features of Lucaogou tight oil reservoir, the experiment methods including scanning electron microscope (SEM), rate-controlled mercury injection (RMI) and pressure-controlled mercury injection (PMI) were performed on the six samples with different lithology. The results indicate that four types of pores exist in Lucaogou tight oil reservoir, including dissolution pores, clay dominated pores, microfractures and inter-granular pores. A combination of PMI and RMI was proposed to calculate the overall PSD of tight oil reservoirs, the overall pore radius of Lucaogou tight oil reservoir ranges from $3.6 \mathrm{~nm}$ to $500 \mu \mathrm{m}$. The fractal analysis was carried out based on the PMI data. Fractal dimension (Fd) values varied between 2.843 and 2.913 with a mean value of 2.88 . Fd increases with a decrease of quartz content and an increase of clay mineral content. Samples from tight oil reservoirs with smaller average pore radius have stronger complexity of pore structure. Fractal dimension shows negative correlations with porosity and permeability. In addition, fractal characteristics of different tight reservoirs were compared and analyzed.
\end{abstract}

Keywords: Tight Oil Reservoir; Pressure-Controlled Mercury Intrusion; Rate-Controlled Mercury Intrusion; Pore Size Distributions; Fractal Dimension.

\section{INTRODUCTION}

The concept of tight oil is originally applied to express oil-bearing tight rocks in the 1940s.1 After that, different research organizations redefined "tight oil" from different views, such as "Oil produced by horizontal drilling technology from shale or other low permeability reservoirs" by Energy Information Administration (EIA) of U.S., 2 and "the oil discovered in low permeability reservoirs" by the Natural Resources Canada (NRC) $[$ Because of the successful exploration and exploitation of tight oil in North America, most of the researchers focused on marine tight oil reservoirs, while the study of lacustrine tight oil plays is still in a relatively poor stage. The research on tight oil in China just begun in the last decade, many tight oil formations were previously considered to be source rock, such as the Lucaogou formation in Junggar Basin, 45 Longmaxi formation in the Sichuan Basin, Basin. ${ }^{910}$ Affected by the commercial development of tight oil in North America, Lucaogou tight oil reservoir were discovered recently and already act as one of the most important tight oil reservoirs in China.11

Microscale pores play a very critical role in controlling the storage capacity and percolation mechanism of oil and gas in the tight reservoirs 1214 Pore size distribution (PSD) is one of most important parts of pore properties, which can influence the interaction of fluid and rock ${ }^{15 / 16}$ However, it is difficult to characterize the pore structure because of the wide PSD from nanoscale to micron scale in tight oil reservoirs. In recent years, many advanced methods have been employed to investigate pore characteristics of rocks, such as Scanning electron microscopy (SEM), 17 19 pressure-controlled mercury injection (PMI) $\stackrel{20}{20}$ nuclear magnetic resonance (NMR), ${ }^{21}$ Low-temperature $\mathrm{N}_{2}$ adsorption (LTNA) and Low-temperature $\mathrm{CO}_{2}$ adsorption (LTCA), 22 X-ray computed tomography $(\mathrm{CT})^{23124}$ and so on. However, it is noteworthy that all these methods have shown advantages and disadvantages in characterizing pore structure of unconventional reservoirs because of their working mechanisms. SEM (including FE-SEM) is an intuitionistic method but cannot obtain accurate quantitative information 25 Traditional mercury injection porosimetry (MIP), obtaining pores information based on the pressure fluctuation, may calculate inaccurately the number of large pores because of the pore blocking effect 26 LTNA and LTCA can distinguish the widely developed small pores, but underestimate the larger pores due to capillary condensation $.20 \mathrm{CT}$ fails to identify the pores with a radius smaller than $50 \mathrm{~nm}$. The pore size distribution from nuclear magnetic resonance (NMR) measurements needs to calibrate 
with MIP data, which results in some errors. Therefore, an integration of variety of methods should be applied to characterize the wide PSD in tight oil reservoirs. Rate-controlled mercury injection (RMI) was proposed by Yuan and Swanson (1989)!27 Pore and throat information can be obtained from mercury injection curves based on the pressure fluctuation, but the small pores (radius $<1.2 \mu \mathrm{m}$ ) will be missed due to the injection pressure limitation $(\sim 6.2 \mathrm{MPa}) \cdot \stackrel{28 \mid 29}{[2 n}$ contrast, PMI can provide small pore throat information.

Since fractal theory was used to study the physical properties and surface characteristics of porous materials, $\stackrel{30}{,}$ more and more researchers applied fractal theory to study the roughness and complexity of pores in coal and shale because of its strong ability to describe the irregular or fragmented shape. ${ }^{22131132}$ In addition, MIP method is commonly used to calculate the Fds. 29

In this paper, the overall PSD of Lucaogou tight oil reservoir was obtained using the combination of PMI and RMI. Fd was calculated and discussed based on MIP data.

\section{SAMPLES AND EXPERIMENTAL METHODS}

\subsection{Samples}

Lucaogou tight oil reservoir is a typical tight oil reservoir, which is located in the southeast region of Junggar Basin.11 As a typical intracontinental superimposed basin, Junggar Basin is in the oil and gas accumulation belt of the piedmont thrust zone. $\frac{33}{}$ Lucaogou Formation is widespread in the entire sag and has a thickness of $300 \mathrm{~m}$. The structure in the sag center is gentle and characterized by the immediate vicinity and near-source reservoirforming of the source-reservoir, where the tight reservoir is concentrated ${ }^{34}$ Lucaogou formation was divided into two sections: $\mathrm{P}_{2} \mathrm{~L}_{1}$ and $\mathrm{P}_{2} \mathrm{~L}_{2}$, the two sections are predominantly composed of tuffaceous siltstone, limy/dolomitic siltstone, silty dolomite, mudstone, etc!11

\subsection{Experimental Methods}

\subsubsection{Porosity and permeability analysis}

The cores were obtained from Lucaogou Formation in the Junggar Basin. The core plugs that were drilled parallel to bedding, need to be removed the residual oil and be dried at $105^{\circ} \mathrm{C}$ for $36 \mathrm{~h}$ in a vacuum environment before carrying out the planned experiments. Porosity and permeability test respectively were performed on ULTRA PORO300 Porosity Tester and ULTRA PERM400 Permeability Tester, following the standard GB/T 29172-2012 of China ${ }^{35}$ Finally, SEM, PMI and RMI experiments were performed on the three parts from the core plugs.

\subsubsection{Scanning electron microscopy}

The pore morphology of samples can be obtained by SEM, which was performed on a Hitachi S4800 scanning electron microscope with a lowest pixel resolution of $1.2 \mathrm{~nm}$ and accelerating voltage of $30 \mathrm{kV}$, following the standard SY/T 5162-2014 of China. ${ }^{36}$ Reducing the surface roughness of samples is needed before the observation, then a Ganta691 Precision Ion Polishing System was used to further argon-ion mill. The thickness of all the samples should be less than $100 \mathrm{~mm}$.

\subsubsection{Pressure-controlled mercury injection}

PMI experiment was carried out on a PoreMaster9500 mercury porosimeter following the standard SY/T 5346-2012 of China. $\frac{37}{3}$ The smallest pore size that this device can measure is about $3.6 \mathrm{~nm}$ when the intrusion pressure reaches $200 \mathrm{MPa}$. A series of characterization parameters were then obtained during the process of slowly increase and decrease of injection pressure, including the maximum, minimum, and average pore-throat radius, Sm, Sr, and $\mathrm{P}_{\mathrm{t}}$ and so on. Intrusion and extrusion curves were obtained in PMI experiments.

\subsubsection{Rate-controlled mercury injection}

RMI is used to quantify the volume and quantities of pore and throat according to the fluctuation of pressure. ${ }^{27 / 38}$ ASPE-730 Rate-controlled mercury porosimeter was employed in the research following the standard SY/T 5346-2012 of China. ${ }^{[37}$ In this experiment, mercury is injected into the samples at an extremely low constant rate $\left(5 \times 10^{-5} \mathrm{~mL} / \mathrm{min}\right)$, and the maximum intrusion pressure is $6.2 \mathrm{MPa}$. Therefore, mercury can only be pressed into the large pores $(>0.12 \mu \mathrm{m})$. The injection volume and pressure are measured precisely in the process of injection of mercury ${ }^{[39}$ By means of the experiment, 
X. Wang et al.

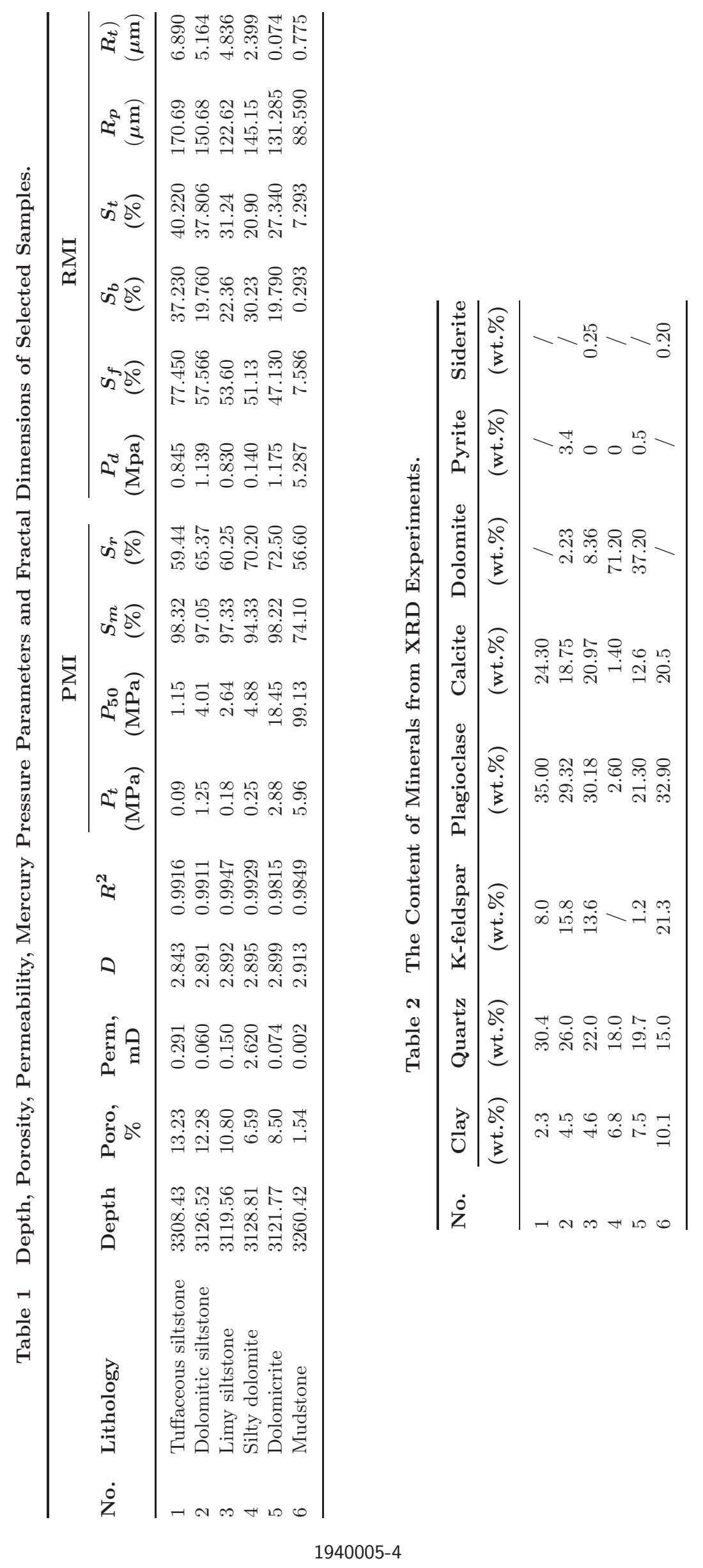


three mercury curves and a variety of characterization parameters, including pore throat radius ratio, throat radius and pore radius were obtained.

\section{RESULTS}

\subsection{Petrophysical Characteristics and Mineralogical Characteristics}

The porosity and permeability data indicated samples from Lucaogou tight oil reservoir generally exhibited poor physical properties (Table 1). Helium porosity of the six samples ranges from $1.54 \%$ to $13.23 \%$ with a mean value of $8.82 \%$. The permeability ranges from $0.002 \mathrm{mD}$ to $2.76 \mathrm{mD}$ with a mean value of $0.53 \mathrm{mD}$ (Table 1). The mineral compositions of samples are shown in Table 2, The quartz, feldspar, and dolomite are the main minerals in these samples. The quartz contents range from $15 \%$ to $30.4 \%$. The plagioclase contents range from $2.6 \%$ to $35 \%$. A small amount of pyrite and siderite exists in some samples.

\subsection{Pore Types}

A total of four types of pores were identified in Lucaogou by SEM observations, which are microfractures, clay dominated pores, dissolution pores and residual inter-particle pores. The long dimensions of these pores are usually more than $15 \mu \mathrm{m}$. The quartz, calcite and feldspar grains were dissolved by fluid to form dissolution pores. Most of the dissolution pores are feldspar dissolution pores (Figs. 1d-1f). Pore morphology of the dissolution pores is determined by the degree of dissolution. In general, the connectivity of the dissolution pores is poor. It is very common that pores within clay aggregates exist in Lucaogou tight oil reservoir, and this type of pores are usually called clay dominated pores. Typical clay minerals found in the samples are chlorite (Figs. 1 $1 \mathrm{i}$ and 1 k), illite-smectite and chlorite-smectite mixed-layer (Figs. 1 $1 \mathrm{~g}$ and $1 \mathrm{~h}$ ). The size of these types of pores is especially small, mainly ranged from $300 \mathrm{~nm}$ to $800 \mathrm{~nm}$. The formation of microfractures is mainly due to the rupture of brittle detrital grains, which are nano-scaled in width and micron-scaled in length.

\subsection{Mercury Injection Porosimetry Curves}

The PMI curves are shown in Fig. 22 and the key parameters from these curves are shown in Table 1 .
All mercury curves have obvious horizontal stages after mercury intrusion, while the length of the horizontal stages is distinctly different. The length of the horizontal stages for the siltstone samples including tuffaceous siltstone, dolomitic siltstone and limy siltstone is larger, and their $P_{t}$ is usually lower than $2 \mathrm{MPa}$, where $P_{t}$ is the threshold pressure, referring to the minimum pressure driving mercury into samples.40 This indicates that the samples with smaller $P_{t}$ have better porethroat sorting. The threshold pressure ranged from $0.09 \mathrm{MPa}$ to $5.96 \mathrm{MPa}$, with an average value of 1.77 MPa. Maximum mercury intrusion saturation $\left(S_{m}\right)$ of samples ranged from $74.1 \%$ to $98.32 \%$, with an average value of $93.23 \%$, the lower $P_{t}$ resulted in the larger maximum mercury intrusion saturation $\left(S_{m}\right)$. After the injection pressure reached the maximum pressure (200 MPa), mercury was gradually withdrawing from the samples with the decrease of pressure. The residual mercury saturation $\left(S_{r}\right)$ ranged from $56.6 \%$ to $72.5 \%$, with a mean value of $64.06 \%$, the samples $\left(P_{t}<2 \mathrm{MPa}\right)$ also have the larger residual mercury saturation $\left(S_{r}\right)$. There was much mercury trapped in the narrow space of samples which showed the great difference between pores and throats.

The RMI curves of the six samples were divided into two types. Based on the difference in lithology, two typical curves of limy siltstone and silty dolomite are displayed in Fig. 3 and microscopic parameters from RMI are listed in Table 1. The threshold pressure $\left(P_{d}\right)$ of Sample 3 was $0.83 \mathrm{MPa}$. The trend of the throat injection curve was consistent with the total injection curve in the initial stages of mercury injection. The throat mercury injection saturation gradually increased with the pressure increased, while an inflection point existed on the pore curve, after which the pore injection curve becomes steep. The $S_{f}$ was $31.24 \%$, which was larger than $S_{b}(22.36 \%)$. On the contrary, the $P_{d}$ of Sample 4 was $0.14 \mathrm{MPa}$, which is smaller than that of Sample 3. The trend of the pore injection curve was consistent with total injection curve in the initial stages of mercury injection. With the pressure increased, pore injection volume of mercury increased slow, and throat injection volume of mercury increased rapidly when the pressure was larger than $3 \mathrm{MPa}$. The $S_{f}$ was $20.9 \%$, which is smaller than $S_{b}(30.23 \%)$. The total mercury saturation increased with the increase of permeability. 

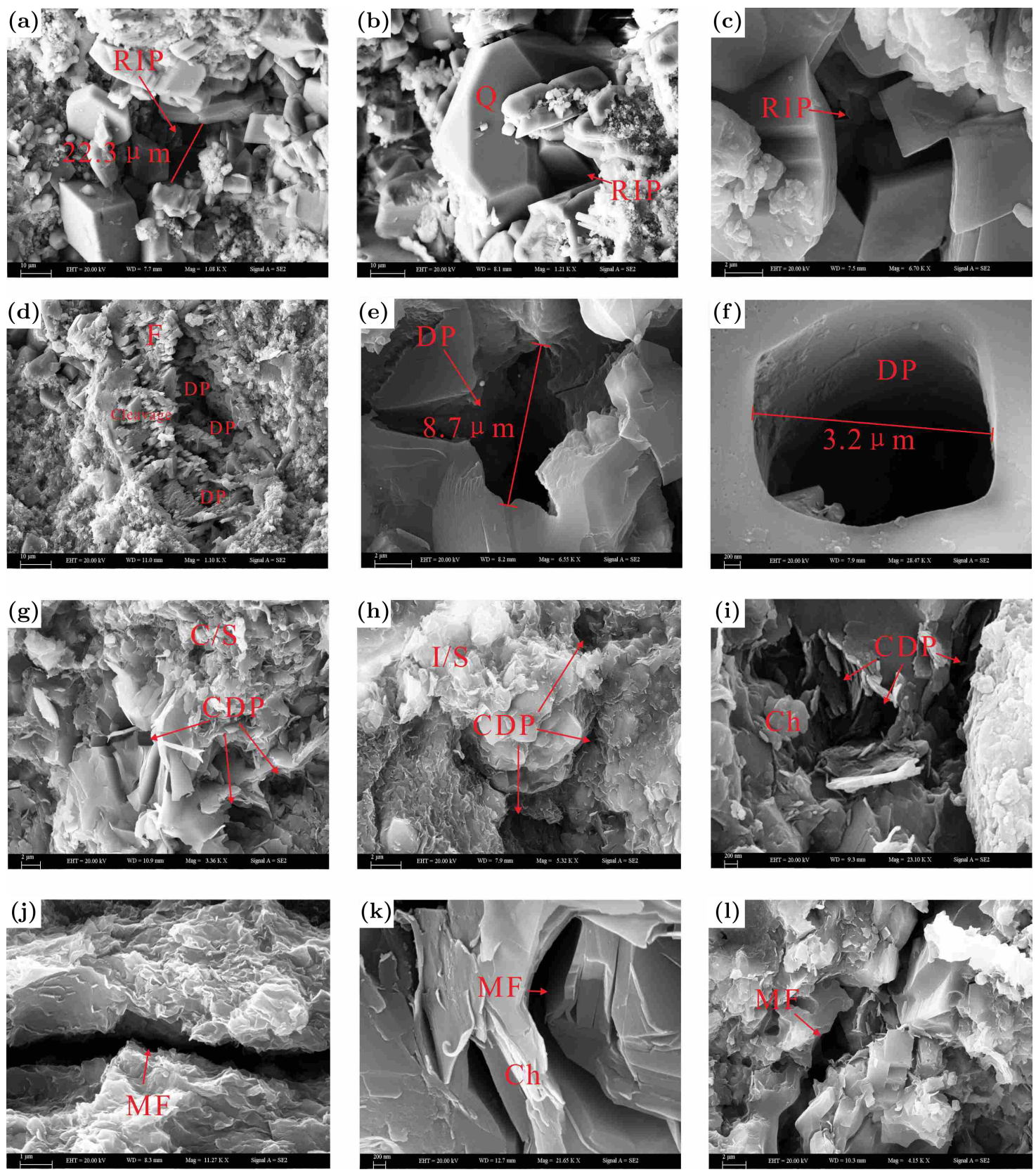

Fig. 1 Pore types in Lucaogou formation. (a)-(c) Residual interparticle pores; (d)-(f) Dissolution pores with irregular geometry; (g) Clay dominated pores of chlorite-smectite layer; (h) Clay dominated pores of mixed illite-smectite layer; (i) Clay dominated pores of chlorite crystal; (j)-(l) Microfractures. $\mathrm{Q}=$ quartz; I/S = Illite-smectite mixed layer; C/S $=$ chloritesmectite mixed layer; $\mathrm{Ch}=$ chlorite $\mathrm{CDP}=$ clay dominated pores; $\mathrm{DP}=$ dissolution pore; $\mathrm{RIP}=$ residual intergranular pore; $\mathrm{MF}=$ microfractures.

\subsection{Fractal Features of Pore System}

The fractal theory was proposed firstly at 1975 by Mandelbrot. ${ }^{30}$ Fractal dimension can well characterize the fragmented or irregular shape of porous complex media.4144 We calculated the Fds of Lucaogou tight oil reservoir using PMI results according to the geometric principle of fractals. The specific calculation process is as follows.
The fractal equation can be expressed as the following equation $\underline{45}$ :

$$
N(>r)=\int_{r}^{r_{m}} P(r) d r=\alpha r^{D},
$$

where $r$ represents the radius of pores, $N(>r)$ is the number of pores and throats (radius $>r$ ),$r_{m}$ is the maximum of the pore radius, $\alpha$ is a proportionality 


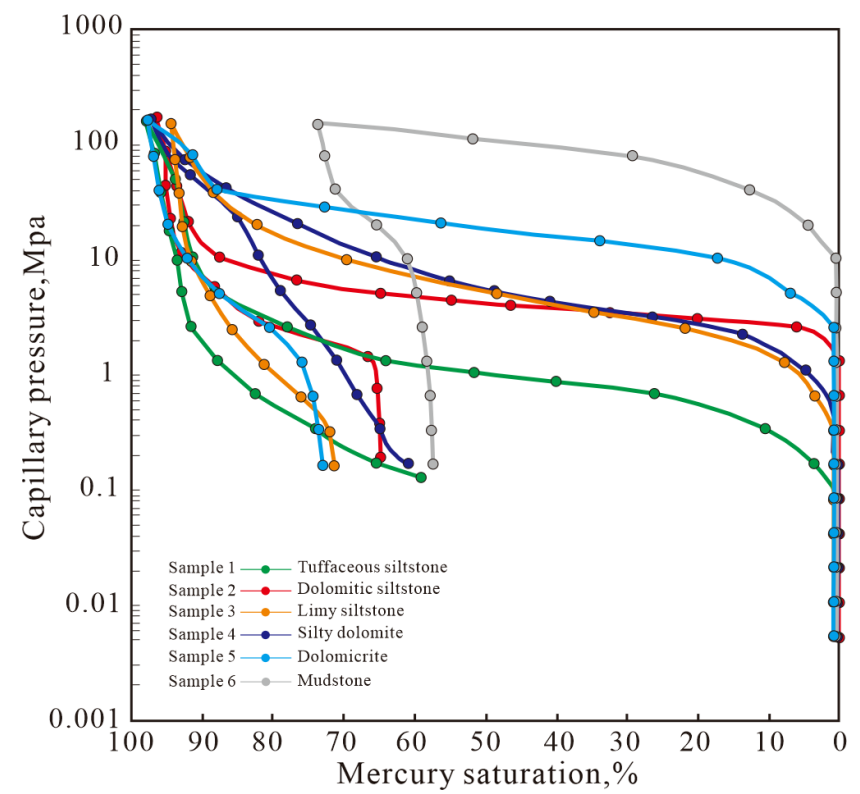

Fig. 2 Intrusion and extrusion curves of PMI.

constant, $P(r)$ is the distribution density function of pore radius, $D$ represents fractal dimension.

The following equation can be obtained from the deduction of Eq. (1) with respect to $r$ :

$$
P(r)=\frac{d N(>r)}{d r}=\alpha^{\prime} r^{-D-1},
$$

where $\alpha^{\prime}$ is a proportionality constant, which is equal to $-D \times \alpha . V(<r)$ (The cumulative volume of the pores and throats) can be calculated by combining Eqs. (2) and (3).

$V(<r)=\int_{r_{s}}^{r} P(r) \alpha r^{3} d r=\alpha^{\prime \prime}\left(r^{3-D}-r_{s}^{3-D}\right)$,

where $r_{s}$ is the minimum of the pore throat radius, $\alpha$ is a constant, $\alpha^{\prime \prime}$ is a proportionality constant, which is equal to $\alpha^{\prime} \times \alpha /(3-D)$.

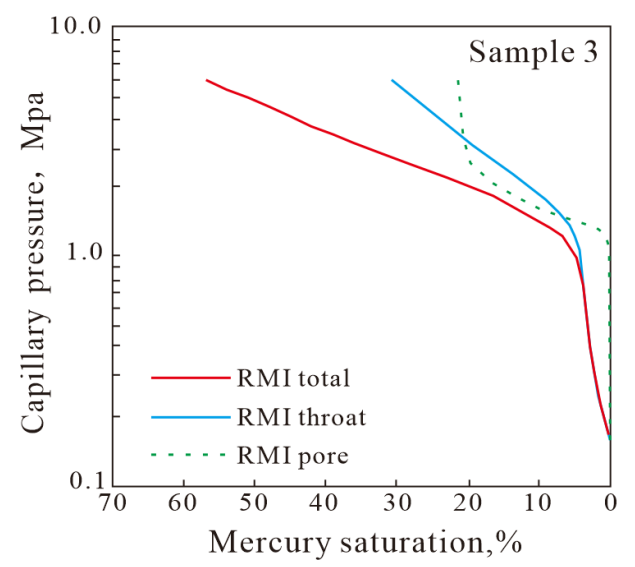

The total pore volume can be expressed as Eq. (44).

$$
V=\alpha^{\prime \prime}\left(r_{m}^{3-D}-r_{s}^{3-D}\right) .
$$

The cumulative volume fraction of pore throats (radius $<r$ ) could be calculated by combining Eqs. (3) and (4).

$$
s=\frac{V(<r)}{V}=\frac{r^{3-D}-r_{s}^{3-D}}{r_{m}^{3-D}-r_{s}^{3-D}} .
$$

Equation (5) can be simplified as the following equation considering $r_{m}$ is much larger than $r_{s}$ :

$$
s=\left(\frac{r}{r_{m}}\right)^{3-D} \text {. }
$$

We could obtain the fractal dimension of pore throat radius distribution considering wetting angle is not influenced by the pore radius.

$$
s=\left(\frac{P_{c}}{P_{\min }}\right)^{D-3} .
$$

The fractal dimension is obtained by taking a logarithm on Eq. (7):

$$
\log \left(1-S_{H g}\right)=(D-3) \log P_{c}-(D-3) \log P_{s} .
$$

Scatter plots can be made using $\log \left(1-S_{H g}\right)$ and $\log (P c)$ as ordinate and abscissa, the slope $K$ can be obtained by fitting a straight line with the scatter points (Fig. (4) and the fractal dimension $D=K+3$. Figure 4 shows three segments of the trend, the third being accurate because PMI has an advantage in obtaining tiny pores information. The larger the fractal dimension, the more complex the pore structure. All $R^{2}$ of the samples are larger than 0.9 (Table 1), which indicates that the pore structure of Lucaogou tight oil reservoir can

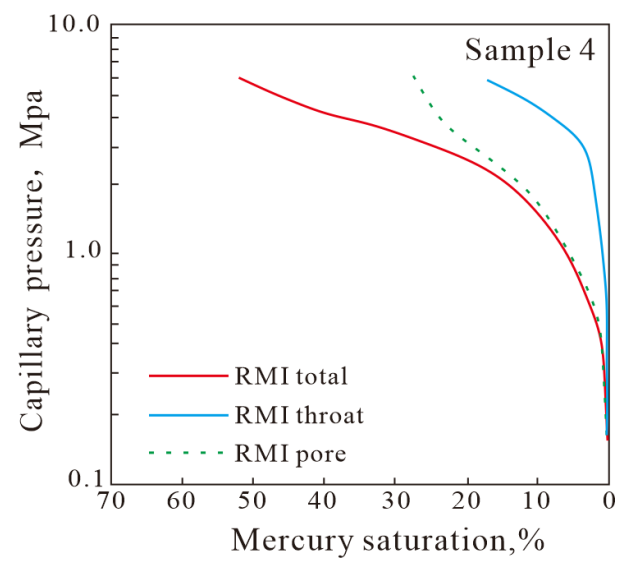

Fig. 3 The total, pore and throat intrusion curves from RMI. 


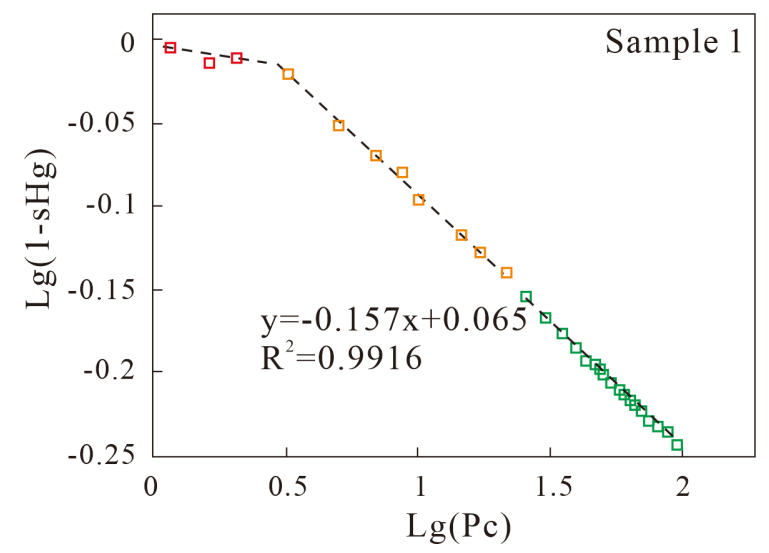

Fig. 4 Fractal dimension curve of Sample 1.

be well characterized using the fractal theory effectively. The fractal dimensions vary between 2.843 and 2.913 with a mean value of 2.88 (Table 1), indicating pore structure of Lucaogou tight oil reservoir have high irregularity.

\section{DISCUSSION}

\subsection{PSD Calculated from PMI and RMI}

The PSD of samples can be calculated from the intrusion curves of PMI ${ }^{10}$ As shown in Fig. 5, the pores throat size of the six samples mainly varied between $3.6 \mathrm{~nm}$ and $40 \mu \mathrm{m}$. The six PSD curves show strong fluctuations when the radius is smaller than $1 \mu \mathrm{m}$, and there are almost no pores with a radius larger than $1 \mu \mathrm{m}$. Only the PSD curve of Sample 1 shows a tiny peak when the pore radius is larger than $10 \mu \mathrm{m}$. Pore size distribution curves of different lithologies have different peaks. The peaks of Sample 5 and Sample 6 ranged from $10 \mathrm{~nm}$ to $50 \mathrm{~nm}$. The peaks of Sample 4 are located in about $0.1 \mu \mathrm{m}$, and that of Samples 1, 2 and 3 mainly varied between $0.2 \mu \mathrm{m}$ and $0.8 \mu \mathrm{m}$. (Fig. 5 ).

We noted that the PSD from PMI was different from SEM results. Many large pores (radius > $1 \mu \mathrm{m})$, which mainly correspond to dissolution pores and residual intergranular pores, exist in the selected samples through SEM observation, this error of PMI is mainly due to the pore blocking effect. When the mercury was forced into the large pores connected by the small throat (such as inkbottle pores), the required injection pressure was very large, which lead to a very small pore radius calculated from the Washburn equation. ${ }^{40}$ Therefore, PMI is not sufficient to characterize the PSD of tight oil reservoirs because of neglecting the large pores, although it seems to have advantages in characterizing nanoscale pores.

Significantly different from PMI, RMI can only measure larger pores because of the limitation of low injection pressure; in addition, pore, throat and pore-throat ratio information can be obtained synchronously from RMI curves (Fig. 6). The six samples had a similar pore radius distribution, indicating that lithology does not affect the pore size distribution a lot. The pore radius mainly ranged between $60 \mu \mathrm{m}$ and $400 \mu \mathrm{m}$ (Fig. 6a); the value of peak was located in about $125 \mu \mathrm{m}$. The pore size of Sample 1 (Tuffaceous siltstone) was the largest, and that of Sample 6 (mudstone) was smallest (Fig. 6a). There is a significant difference in the distribution of the throat size of samples of different lithology; this may indicate that lithology could be a potential factor that controlled the distribution of the throat

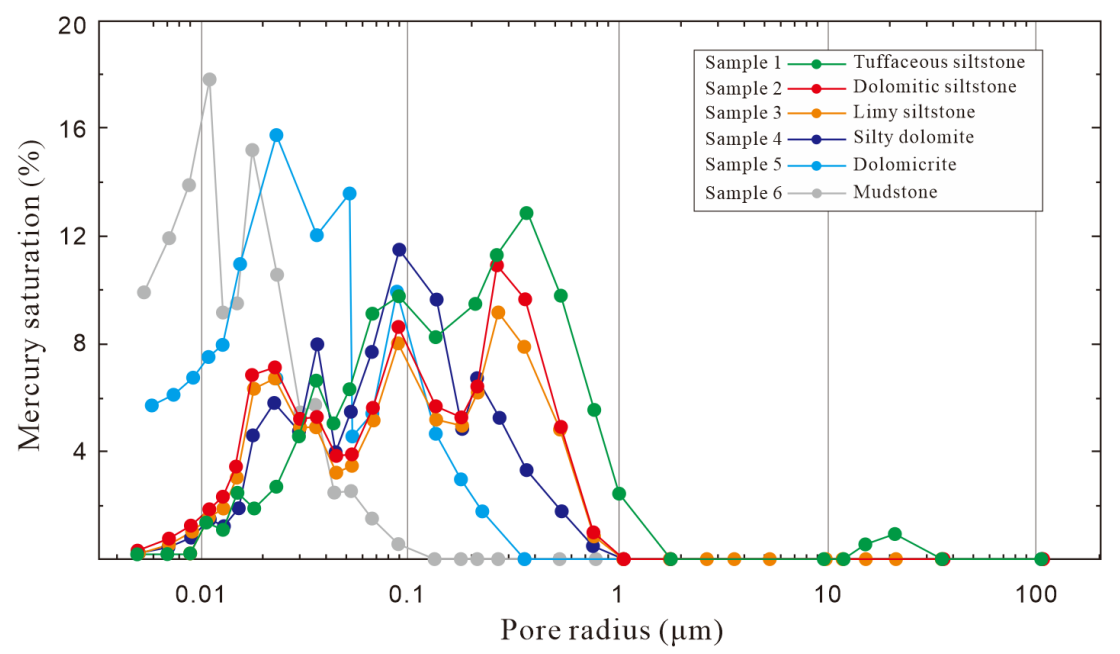

Fig. 5 PSD curves calculated from PMI. 


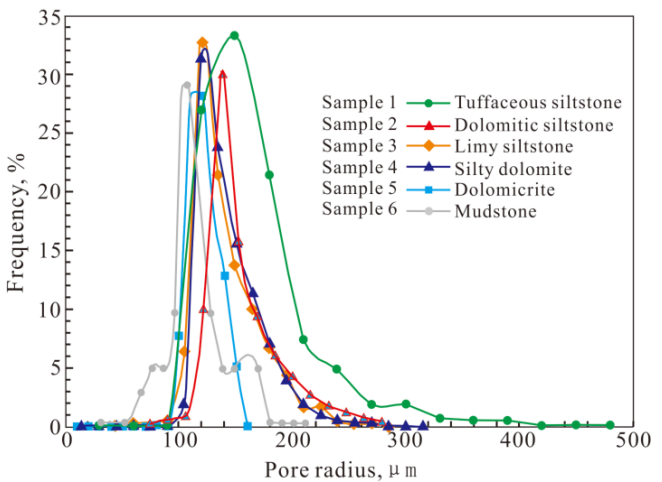

(a)

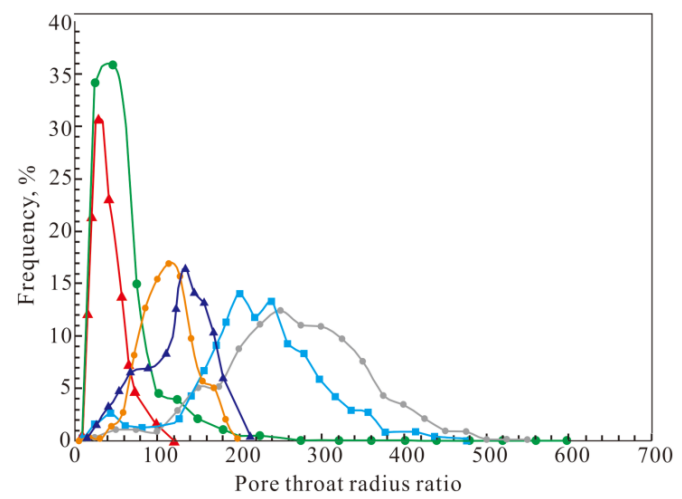

(c)

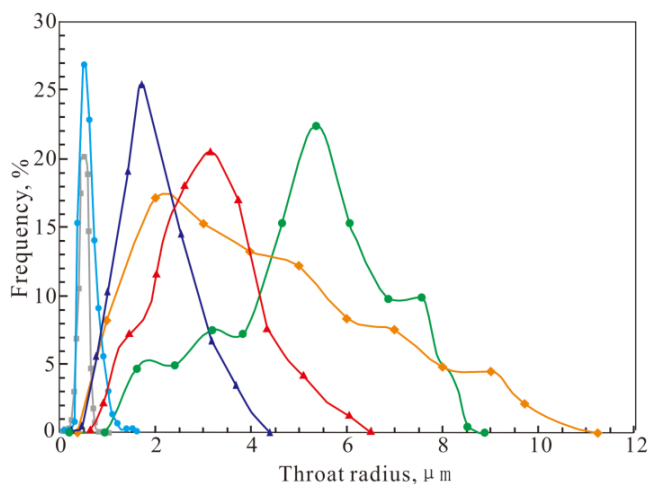

(b)

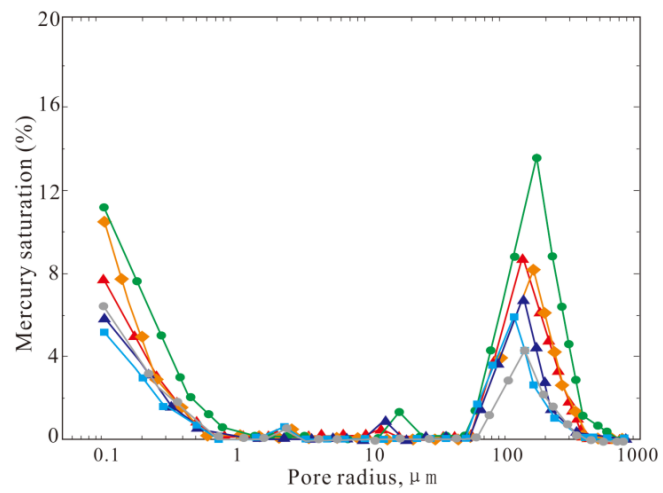

(d)

Fig. 6 Pore radius, throat radius and pore-throat ratio from RMI of the six samples: (a) Pore radius distribution; (b) Throat radius distribution; (c) Pore-throat ratio distribution; (d) Pore size distribution.

size. The throat distribution ranged from $0.1 \mu \mathrm{m}$ to $12 \mu \mathrm{m}$. The peak value of samples of $1,2,3$ and 4 was concentrated in between $2 \mu \mathrm{m}$ and $6 \mu \mathrm{m}$, and that of two other samples was around $1 \mu \mathrm{m}$. The throat size distribution of Sample 3 (Limy siltstone) was widest while that of Sample 6 was most narrow. The pore-throat ratio ranged from 30 to 600 , the wide distribution range and the large value of pore-throat ratio were due to significant pore and throat size difference. The large pore throat difference (large pore spaces and small throat size) causes the extremely low permeability of tight oil reservoirs.

PSD from RMI result was shown in Fig. 6 d. All the PSD curves of different lithology samples contained two peaks, one left semi-peak, and one right peak. The left semi-peak had a similar trend but no wave peak value, the right peak value was distributed between $60 \mu \mathrm{m}$ and $400 \mu \mathrm{m}$, which was in line with the results of the SEM. The average final injection mercury saturation is only about $50 \%$ (Table प), which indicated that RMI was unable to characterize tiny pores ( radius $<0.12 \mu \mathrm{m}$ ).

\subsection{Recommended Method to Calculate the Overall PSD}

Although there are some small differences, the mercury pressure curves obtained by PMI and RMI are roughly the same (Fig. 7). According to the discussion above, wide PSD in tight oil reservoirs made it inadequate to characterize the overall PSD by only one test method. PMI can obtain small pore throat information but underestimate large pores. RMI can characterize large pores but fails to identify tiny pores (radius $<0.12 \mu \mathrm{m}$ ). The two methods are complementary in calculating the pore range in tight oil reservoirs so that the combination of the two methods could effectively obtain the overall pore size information.

The overall PSD of Lucaogou formation is characterized by multiple peaks, and its pore radii range from $3.6 \mathrm{~nm}$ to $400 \mu \mathrm{m}$ (Fig. 8). All PSD curves of samples are composed of two distinct peaks. The right peak is mainly distributed in $80-300 \mu \mathrm{m}$ with a peak value of $\sim 110 \mu \mathrm{m}$. The part corresponds to the dissolution pores and the residual intergranular 


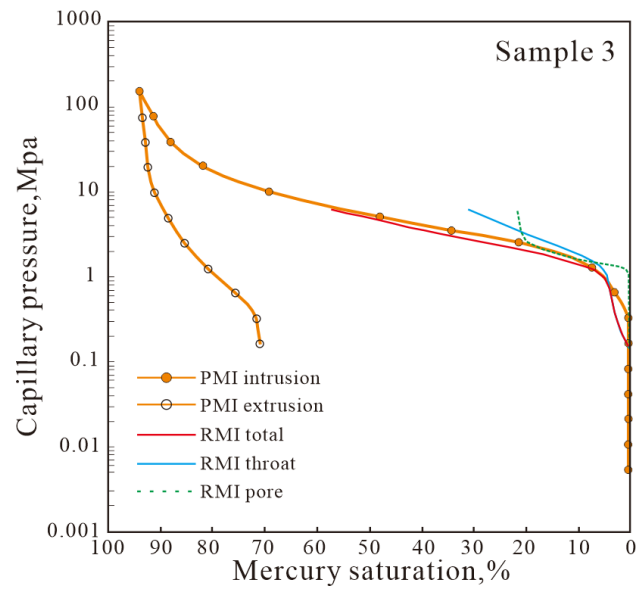

(a)

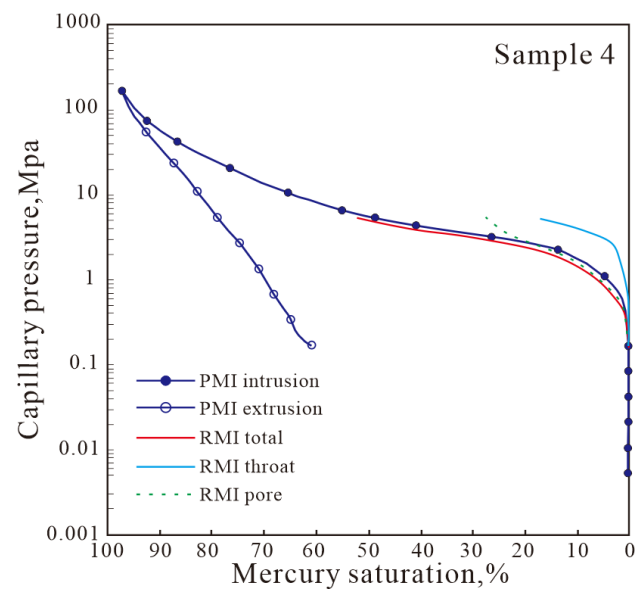

(b)

Fig. 7 Comparison of mercury pressure curves from PMI and RMI conducted on Sample 3 and Sample 4.

pores, obtained from RMI. The left peak value was mainly distributed in $3.6 \mathrm{~nm}-200 \mathrm{~nm}$, which was obtained from PMI. The fluctuation of the left peak of PSD curve was extreme, which indicates that there are great differences in the size distribution characteristics of tiny pores (quantity, morphology, etc.) of different samples. The left peak value of Samples (1-4) was about $100 \mathrm{~nm}$, larger than that of the other two samples, demonstrating more tiny pores $(<100 \mathrm{~nm})$ exist in dolomicrite and mudstone samples. Pores are divided into macropores $(>2 \mathrm{~mm}$ in radius), mesopores $(30 \mu \mathrm{m}-2 \mathrm{~mm})$, micropores $(0.5 \mu \mathrm{m}-30 \mu \mathrm{m})$, and nanopores $(<500 \mathrm{~nm}) \stackrel{46}{[}$ The two main pore size types in Lucaogou tight oil reservoir are nanopores and mesopores.

\subsection{Analysis of Fractal Characteristics}

\subsubsection{Relationship between mineral composition and $\boldsymbol{F d}$}

From the results of Fds in Table 1 fractal dimensions $(D)$ of different lithology samples are significant different. Fractal dimension of tuffaceous siltstone sample is the largest compared to other lithology samples. Fractal dimension of samples (dolomitic siltstone, limy siltstone and silty dolomite) is concentrated in about 2.893, indicating these lithology samples have similar complexity of pore structure. Sample 6 (mudstone) has the most complex pore structures with $D$ of 2.9137 . To study the potential factors that affect the fractal characteristics of the rocks, the relationship between mineral composition and $\mathrm{Fd}$ is investigated (Fig. 9). Fd increases with a decrease in quartz content (Fig. 9a). This is because the more the quartz content, the larger the probability of developing intergranular pores. The intergranular pores have relatively small complexity. Fd increases with and an increase in clay content (Fig. 9p). This is

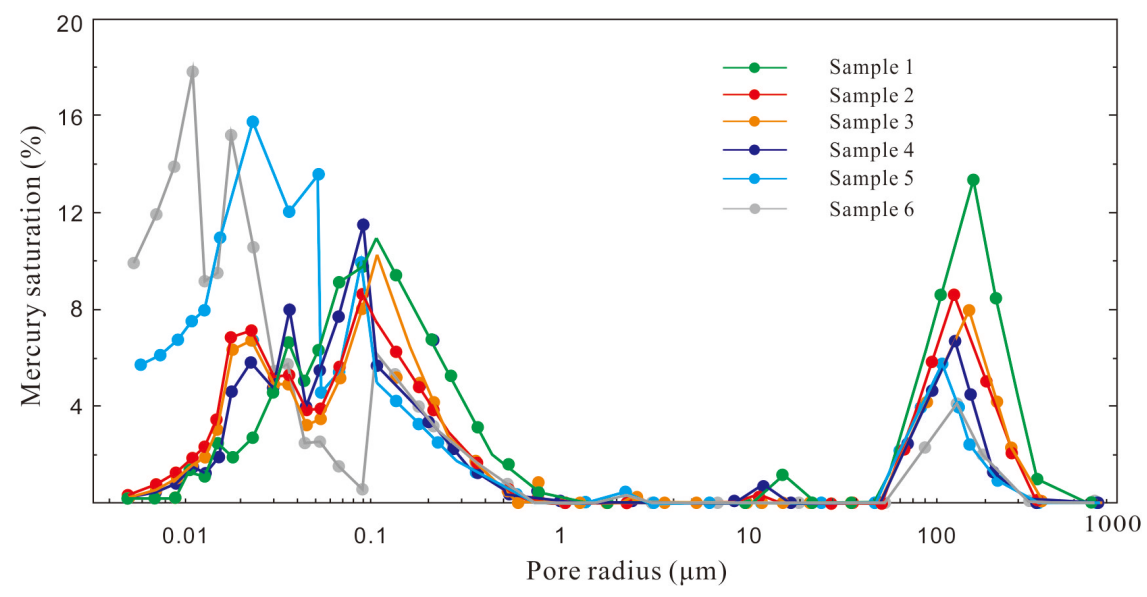

Fig. 8 PSD obtained from the combination of RMI and PMI. 


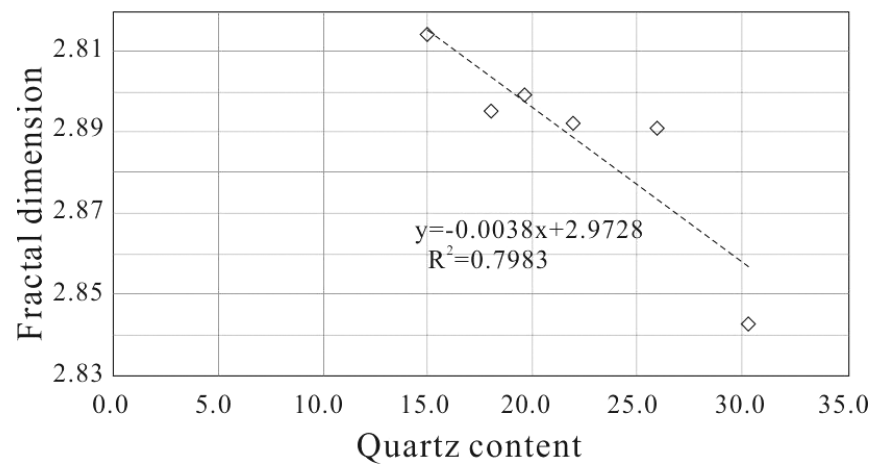

(a)

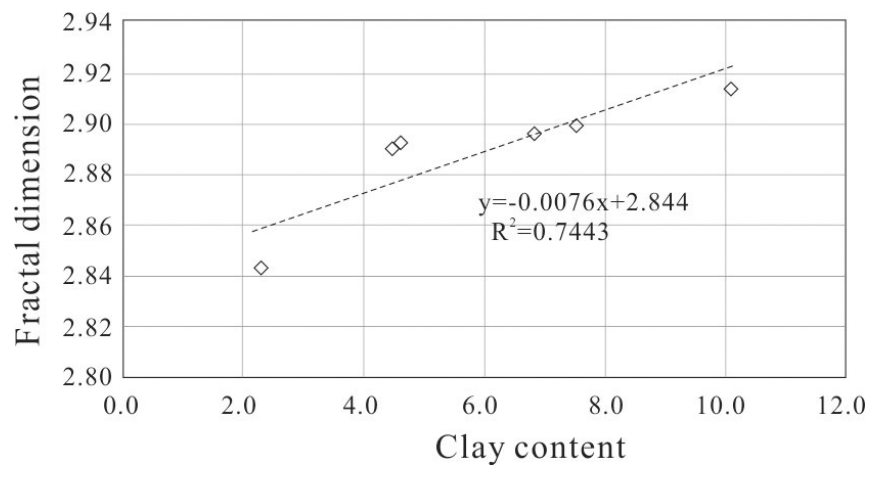

(b)

Fig. 9 Relationships between (a) quartz content, (b) clay content and fractal dimension.

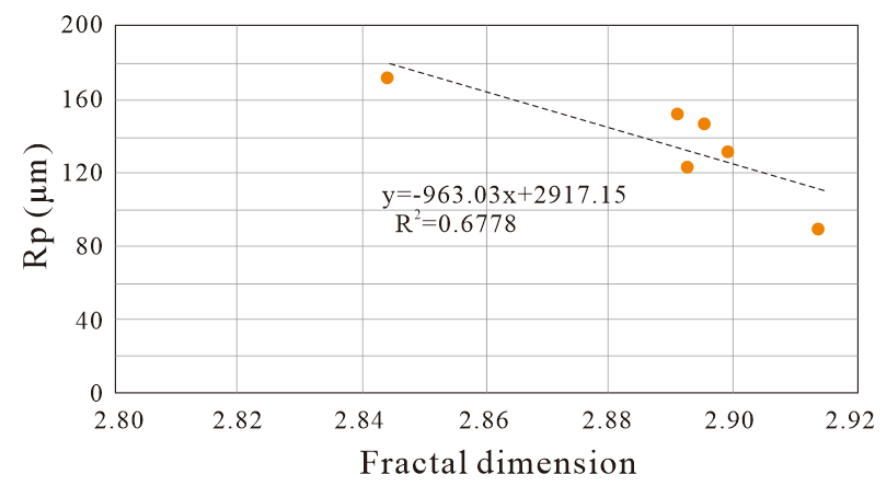

(a)

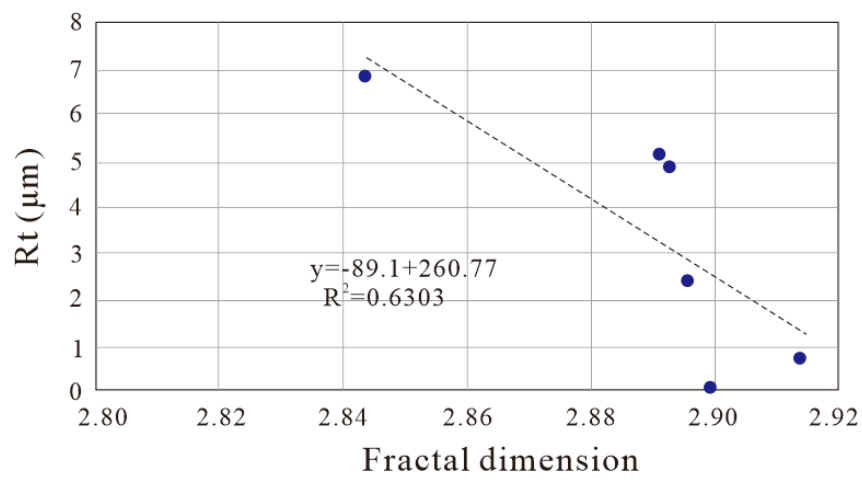

(b)

Fig. 10 Relationships between (a) $R_{p}$, (b) $R_{t}$ and $\mathrm{Fd}$.

due to the fact that abundant pores exist in the clay minerals. The size of clay dominated pores is tiny, and the pore morphology is complicated and various (Fig. 1), which leads to complex pore structure.

\subsubsection{Relationship between pore structure parameters and $\boldsymbol{F d}$}

Figure 10 shows a good relationship between $D$ and $R_{p}$ and $R_{f}$, with correlation coefficients of 0.6778 and 0.6303 , respectively. Fd increases with a decreasing of $R_{p}$ and $R_{f}$. This discovery is consistent with the previous results. This means that tight oil reservoirs with smaller average pore radius would have stronger complexity of pore structure. It can be seen in Fig. 11] there is a negative correlation between $\mathrm{Fd}$ and $S_{m}$ with a correlation coefficient of 0.305. $S_{m}$ is gradually decreased with an increase of $\mathrm{Fd}$. Which indicates that stronger complexity of pore structure leads to smaller effective storage space and lower charging efficiency of oil and gas. Through the above analysis, tight oil reservoirs with smaller average pore radius would have

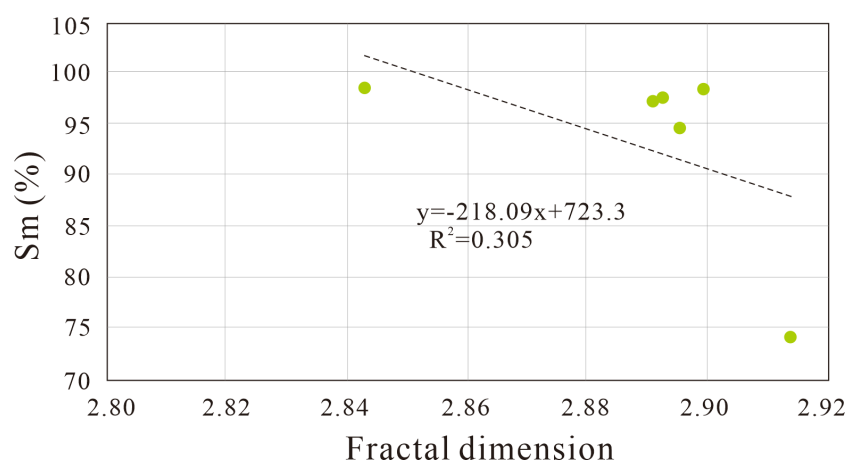

Fig. 11 Relationships between $S_{m}$ and Fd.

smaller effective storage space and lower hydrocarbon charging efficiency.

\subsubsection{Relationship between reservoir quality and $\boldsymbol{F d}$}

The relationships between the porosity, permeability and $\mathrm{Fd}$ are established to explore the influence of fractal dimension on reservoir quality (Fig. 12). According to Fig. [12a, fractal dimension showed a negative correlation with the porosity with a $R^{2}$ of 


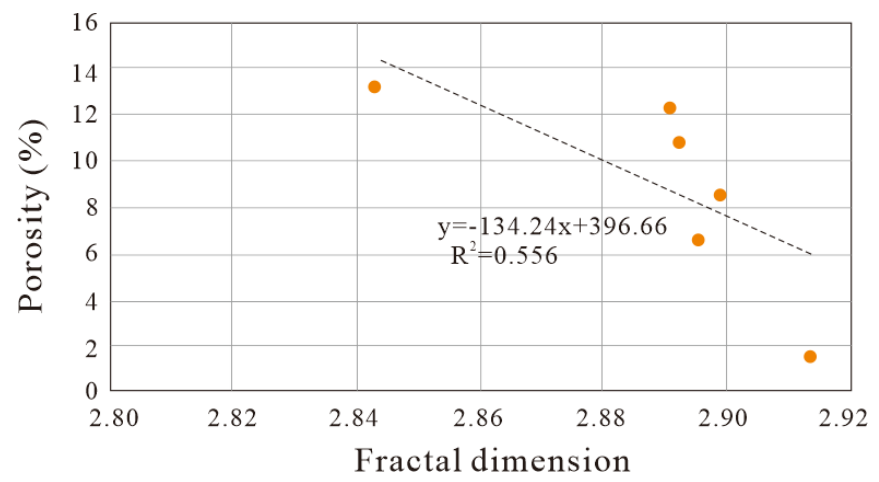

(a)

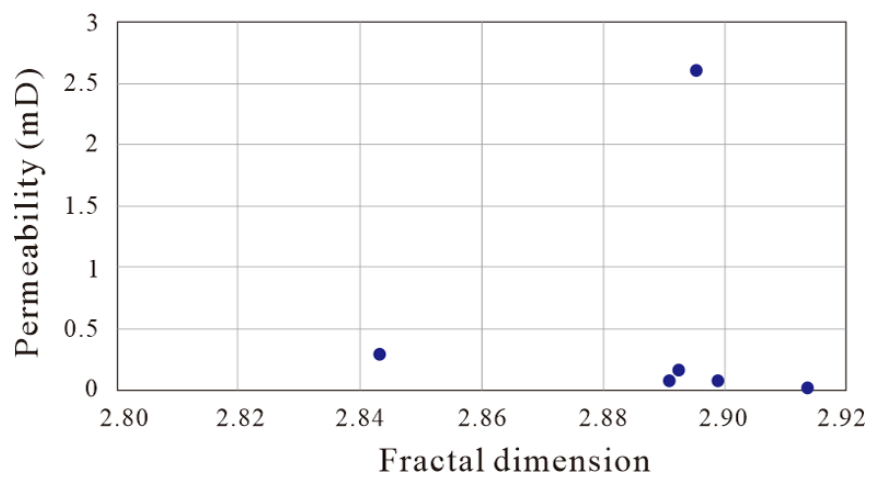

(b)

Fig. 12 Relationships between (a) porosity, (b) permeability and fractal dimension.

0.556, which indicates that in Lucaogou tight oil reservoir, higher complexity of pore structure leads to poor storage capacity. This finding is same to the discussion results of Sec. 4.4.2. Besides, there was no obvious relationship between $D$ and permeability (Fig. 12b), while it is worth noting that only one data point (Sample 4) deviated from the whole rule line. There is a good negative correlation between $D$ and permeability if the data point is removed, this is interpreted as the higher complexity of pore structure leading to poor flow capacity of Lucaogou tight oil reservoir.

\subsubsection{Comparison of fractal characteristics of different tight reservoirs}

Fractal characteristics of Lucaogou tight oil reservoir have been compared to other four typical tight reservoirs (Table 3). As is seen from the table, the pore structure of these tight reservoirs is complex with fractal dimension ranging from 2.49 to 2.88 . Fractal dimension of Lucaogou tight oil reservoir is largest because of the complex lithology. Quantou formation is an important tight reservoir in Songliao Basin, China, with the fractal dimension of 2.78 , which shows strong complexity of pore structure. The fractal characteristics and main controlling factors are similar to Lucaogou tight oil reservoir. Bakken formation is one of the largest tight oil reservoirs located in the Williston Basin, USA. Bakken formation acts also an important source of oil and gas, with a high content of TOC $(>10 \%) ! 22$ The fractal dimension is about 2.62, smaller than that of Lucaogou and Quantou tight oil reservoirs, which means pore structure of Lucaogou tight oil reservoir is more complex than Bakken tight oil reservoir. Chang 7 formation and Shihezi formation

Table 3 Fractal Characteristics of Different Tight Reservoirs. $22[29 \sqrt{4447}$

\begin{tabular}{|c|c|c|c|c|c|c|c|c|c|c|c|c|}
\hline \multirow{4}{*}{$\begin{array}{l}\text { Country } \\
\text { Basin } \\
\text { Formation } \\
\text { Fractal } \\
\text { dimension }\end{array}$} & \multicolumn{12}{|c|}{ China } \\
\hline & \multicolumn{3}{|c|}{ Junggar } & \multicolumn{3}{|c|}{ Songliao } & \multicolumn{6}{|c|}{ Ordos } \\
\hline & \multicolumn{3}{|c|}{ Lucaogou } & \multicolumn{3}{|c|}{ Quantou } & \multicolumn{3}{|c|}{ Shihezi } & \multicolumn{3}{|c|}{ Chang7 } \\
\hline & $\begin{array}{l}\operatorname{Max} \\
2.91\end{array}$ & $\begin{array}{l}\text { Min } \\
2.84\end{array}$ & $\begin{array}{c}\text { Mean } \\
2.88\end{array}$ & $\begin{array}{l}\text { Max } \\
2.98\end{array}$ & $\begin{array}{l}\text { Min } \\
2.35\end{array}$ & $\begin{array}{l}\text { Mean } \\
2.75\end{array}$ & $\begin{array}{l}\text { Max } \\
2.89\end{array}$ & $\begin{array}{l}\text { Min } \\
2.02\end{array}$ & $\begin{array}{l}\text { Mean } \\
2.56\end{array}$ & $\begin{array}{l}\operatorname{Max} \\
2.66\end{array}$ & $\begin{array}{l}\text { Min } \\
2.20\end{array}$ & $\begin{array}{c}\text { Mean } \\
2.53\end{array}$ \\
\hline Country & \multicolumn{12}{|c|}{ USA } \\
\hline $\begin{array}{l}\text { Basin } \\
\text { Formation }\end{array}$ & \multicolumn{12}{|c|}{$\begin{array}{l}\text { Williston } \\
\text { Bakken }\end{array}$} \\
\hline & \multicolumn{4}{|c|}{ Upper Bakken } & \multicolumn{4}{|c|}{ Middle Bakken } & \multicolumn{4}{|c|}{ Lower Bakken } \\
\hline $\begin{array}{l}\text { Fractal } \\
\quad \text { dimension }\end{array}$ & $\begin{array}{l}\mathrm{Ma} \\
2.7\end{array}$ & & $\begin{array}{l}\text { Min } \\
2.62\end{array}$ & $\begin{array}{c}\text { Mean } \\
2.7\end{array}$ & $\begin{array}{l}\mathrm{M} \\
2 .\end{array}$ & & $\begin{array}{l}\text { Min } \\
.30\end{array}$ & $\begin{array}{c}\text { Mean } \\
2.49\end{array}$ & $\begin{array}{l}\mathrm{Ma} \\
2.7\end{array}$ & & $\begin{array}{l}\text { Min } \\
2.69\end{array}$ & $\begin{array}{c}\text { Mean } \\
2.7\end{array}$ \\
\hline
\end{tabular}


are the typical tight reservoirs of Ordos Basin, China ${ }^{2947}$ The fractal dimensions are 2.56 and 2.53 respectively, smaller than that of Lucaogou and Quantou tight reservoirs.

With the maturation of organic matter, a large number of organic pores are produced, and the complexity of organic pores is poor compared to clay dominated pores $\frac{[32]}{\text { It }}$ can be summed up that the existence of organic matter leads to the poor complexity of pore structure. Overall, tight reservoirs have strong complex pore structure. Fractal theory can be used to effectively characterize the pore complexity of tight reservoirs. The tight reservoirs have different fractal characteristics due to different control factors. Clay content and brittle mineral content are the main controlling factors of fractal characteristics for tight stratums which only act as reservoirs.

\section{CONCLUSIONS}

(1) The pores in Lucaogou formation are divided into four types, microfractures, clay dominated pores, dissolution pores and residual interparticle pores. The size of dissolution pores and interparticle pores was larger, in comparison with clay dominated pores.

(2) The overall PSD was calculated under the method of combination of PMI and RMI. The overall PSD of different lithologies is distinctly different, which is polymodal and the pore radii vary between $3.6 \mathrm{~nm}$ and $500 \mu \mathrm{m}$. The dolomicrite and mudstone samples have most tiny pores $(<100 \mathrm{~nm})$.

(3) Fd values are distributed in between 2.843 and 2.913 with a mean value of 2.88 , showing a rather complex pore system. Clay content and quartz content are two main factors controlling pore system in which pore system controls the reservoir quality of Lucaogou tight oil reservoir.

(4) Different tight reservoirs have different fractal characteristics due to a variety of control factors. Clay content, brittle mineral content are main controlling factors of fractal characteristics for tight stratums which only act as a reservoir.

\section{ACKNOWLEDGMENT}

This work was supported by National Basic Research Program of China (No. 2015CB250901), the China National Science and Technology Major
Project (Nos. 2016ZX05010-001, 2016ZX05014002008), and the Foundation of State Key Laboratory of Petroleum Resources and Prospecting, China University of Petroleum, Beijing (No. PRP/open1601).

\section{ABBREVIATIONS}

$\mathrm{MIP}=$ Mercury injection porosimetry

$\mathrm{RMI}=$ Rate-controlled mercury injection

$\mathrm{PMI}=$ Pressure-controlled mercury injection

$\mathrm{PSD}=$ Pore size distribution

FE-SEM $=$ Field emission scanning electron microscopy

SEM = Scanning electron microscopy

$\mathrm{NMR}=$ Nuclear magnetic resonance

LTNA $=$ Low-temperature $\mathrm{N}_{2}$ adsorption

LTCA $=$ Low-temperature $\mathrm{CO}_{2}$ adsorption

$\mathrm{CT}=\mathrm{X}$-ray computed tomography

EIA = Energy Information Administration

$\mathrm{NRC}=$ Natural Resources Canada

$\mathrm{Fd}=$ Fractal dimension

$S_{r}=$ Residual mercury saturation

$S_{m}=$ Maximum mercury saturation

$P_{t}=$ Threshold pressure of PMI

$P_{50}=$ medium saturation pressure

$R_{t}=$ Average throat radius

$R_{p}=$ Average pore radius

$P_{d}=$ Threshold pressure of RMI

$S_{t}=$ Throat body mercury intrusion saturation

$S_{f}=$ Final mercury intrusion saturation

$S_{b}=$ Pore body mercury intrusion saturation

$R^{2}=$ Correlation coefficient.

\section{REFERENCES}

1. G. W. Ledingham, Santiago Pool, Kern County, California: Geological notes, AAPG Bull. 31 (1947) 2063-2067.

2. Energy information administration, Department of Energy (2010).

3. Natural Resources Canada, North American tight light oil (2014).

4. Q. Y. Luo, L. Gong, Y. S. Qu, K. H. Zhang, G. L. Zhang and S. Z. Wang, The tight oil potential of the Lucaogou formation from the southern Junggar basin, China, Fuel 234 (2018) 858-871.

5. L. Wang, N. Zhao, L. Sima, F. Meng and Y. Guo, Pore structure characterization of the tight reservoir: A systematic integration of mercury injection and nuclear magnetic resonance, Energy Fuels 32 (2018) 7471-7484.

6. S. B. Chen et al., Characteristics and significance of mineral compositions of Lower Silurian Longmaxi 
formation shale gas reservoir in the southern margin of Sichuan basin, Acta Pet. Sin. 32(5) (2011) 775782 .

7. K. Jiao et al., The characterization and quantitative analysis of nanopores in unconventional gas reservoirs utilizing FESEM-FIB and image processing: An example from the lower Silurian Longmaxi Shale, upper Yangtze region, China, Int. J. Coal Geol. 128 (2014) 1-11.

8. M. Sun et al., Pore characteristics of Longmaxi shale gas reservoir in the Northwest of Guizhou, China: Investigations using small-angle neutron scattering (SANS), helium pycnometry, and gas sorption isotherm, Int. J. Coal Geol. 171 (2017) 61-68.

9. J. L. Yao et al., Characteristics of tight oil in Triassic Yanchang formation, Ordos Basin, Pet. Explor. Dev. 2 (2013) 161-169.

10. H. Wu et al., Insight into the pore structure of tight gas sandstones: A case study in the Ordos basin, NW China, Energy Fuels 31(12) (2017) 13159-13178.

11. Z. Cao et al., Lacustrine tight oil accumulation characteristics: Permian Lucaogou formation in jimusaer sag, Junggar basin, Int. J. Coal Geol. 153 (2016) 37-51.

12. L. M. Anovitz and D. R. Cole, Characterization and analysis of porosity and pore structures, Rev. Mineral. Geochem. 80(1) (2015) 61-164.

13. P. Zhao, J. Cai, Z. Huang, M. Ostadhassan and F. Ran, Estimating permeability of shale-gas reservoirs from porosity and rock compositions, Geophysics 83 (2018) MR283-MR294.

14. D. Xiao et al., Combining rate-controlled porosimetry and NMR to probe full-range pore throat structures and their evolution features in tight sands: A case study in the Songliao Basin, China, Mar. Pet. Geol. 83 (2017) 111-123.

15. D. Sanyal, P. Ramachandrarao and O. P. Gupta, A fractal description of transport phenomena in dendritic porous network, Chem. Eng. Sci. 61(2) (2006) 307-315.

16. A. L. Eberle et al., High-resolution, high-throughput imaging with a multibeam scanning electron microscope, J. Microsc. 259(2) (2015) 114-120.

17. X. Wang et al., Studying reservoir heterogeneity by analytic hierarchy process and fuzzy logic, case study of Es1x formation of the Wang guan tun oilfield, China, J. Pet. Sci. Eng. 156 (2017) 858-867.

18. X. Wang et al., Combining pressure-controlled porosimetry and rate-controlled porosimetry to investigate the fractal characteristics of full-range pores in tight oil reservoirs, J. Pet. Sci. Eng. 171 (2018) 353-361.

19. X. Shao et al., Pore structure and fractal characteristics of organic-rich shales: A case study of the lower Silurian Longmaxi shales in the Sichuan basin, SW China, Mar. Pet. Geol. 80 (2017) 192-202.
20. D. Xiao et al., Comparison and integration of experimental methods to characterize the full-range pore features of tight gas sandstone - A case study in Songliao basin of China, J. Nat. Gas Sci. Eng. 34 (2016) 1412-1421.

21. P. Zhao et al., Investigation on the pore structure and multifractal characteristics of tight oil reservoirs using NMR measurements: Permian Lucaogou formation in Jimusaer Sag, Junggar basin, Mar. Pet. Geol. 86 (2017) 1067-1081.

22. K. Liu et al., Nanoscale pore structure characterization of the Bakken shale in the USA, Fuel 209 (2017) 567-578.

23. S. Hemes et al., Multi-scale characterization of porosity in Boom Clay (HADES-level, Mol, Belgium) using a combination of X-ray $\mu$-CT, $2 \mathrm{D}$ BIB-SEM and FIB-SEM tomography, Microporous Mesoporous Mater. 208 (2015) 1-20.

24. L. Kong et al., Pore characterization of 3D-printed gypsum rocks: A comprehensive approach, J. Mater. Sci. 53 (2018) 1-16.

25. J. Klaver et al., BIB-SEM study of the pore space morphology in early mature Posidonia shale from the Hils area, Germany, Int. J. Coal Geol. 103 (2012) 12-25.

26. J. Kaufmann, R. Loser and A. Leemann, Analysis of cement-bonded materials by multi-cycle mercury intrusion and nitrogen sorption, J. Colloid Interface Sci. 336 (2009) 730-736.

27. H. H. Yuan and B. F. Swanson, Resolving pore-space characteristics by rate-controlled porosimetry, SPE Form. Eval. 4(1) (1989) 17-24.

28. L. Sima et al., Effect of pore structure on the seepage characteristics of tight sandstone reservoirs: A case study of Upper Jurassic Penglaizhen Fm reservoirs in the western Sichuan basin, Nat. Gas Ind. 4(1) (2017) 17-24.

29. W. Huang et al., Reservoir spaces in tight sandstones: Classification, fractal characters, and heterogeneity, J. Nat. Gas Sci. Eng. 46 (2017) 80-92.

30. B. Mandelbrot, Les Objects Fractals: Forme, Hasard et Dimension (Flammarion, Paris, 1975).

31. M. E. Curtis, B. Cardott and C. Sondergeld, Development of organic porosity in the Woodford Shale with increasing thermal maturity, Int. J. Coal Geol. 103 (2012) 26-31.

32. M. Sun et al., Nanoscale pore characteristics of the lower Cambrian Niutitang formation shale: A case study from Well Yuke\# 1 in the southeast of Chongqing, China, Int. J. Coal Geol. 154 (2016) 1629.

33. J. A. Shi et al., Geochemical characteristics and genetic mechanism of permian dolomitic clastic rocks in Northwestern Junggar basin, Acta Sedimentol. Sin. 31 (2013) 898-906. 
34. L. C. Kuang et al., Formation conditions and exploration potential of tight in the Permian saline lacustrine dolomitic rock, Junggar basin, NW China, Pet. Explor. Dev. 39 (2012) 657-667.

35. GB/T 29172-2012 of China, Practices for core analysis (2012).

36. SY/T 5162-2014 of China, Analytical method of rock sample by scanning electron microscope (2014).

37. SY/T 5346-2012 of China, Rock capillary pressure measurement (2012).

38. C. Gaulier, Studying vugular rocks by-constant-rate mercury injection, SPE (1971), pp. 1-7.

39. Y. Sun et al., The nano throats characteristics of tight sandstone in the fourth section of cretaceous quantou formation, Da'an Terrace of Songliao basin, Northeast China, J. Nanosci. Nanotechnol. 17(9) (2017) 6235-6241.

40. L. Thomas, D. Katz and M. R. Tek, Threshold pressure phenomena in porous media, Soc. Pet. Eng. J. 8 (1968) 174-84.

41. M. Jaroniec, Evaluation of the fractal dimension from a single adsorption isotherm, Langmuir 11(6) (1995) 2316-2317.
42. J. Cai et al., Fractal characterization of dynamic fracture network extension in porous media, Fractals 25(2) (2017) 1750023.

43. W. Wei, J. Cai, X. Hu and Q. Han, An electrical conductivity model for fractal porous media, Geophys. Res. Lett. 42(12) (2015) 4833-4840.

44. X. Shao et al., Reservoir characterization of tight sandstones using nuclear magnetic resonance and incremental pressure mercury injection experiments: Implication for tight sand gas reservoir quality, Energy Fuels 31(10) (2017) 10420-10431.

45. B. B. Mandelbrot, D. E. Passoja and A. J. Paullay, Fractal character of fracture surfaces of metals, Nature 308(5961) (1984) 721-722.

46. R. G. Loucks, R. M. Reed, S. C. Ruppel and U. Hammes, Spectrum of pore types and networks in mudrocks and a descriptive classification for matrixrelated mudrock pores, AAPG Bull. 96(6) (2012) 1071-1098.

47. F. Jiang et al., Fractal analysis of shale pore structure of continental gas shale reservoir in the ordos basin, NW China, Energy Fuels 30(6) (2016) 46764689 . 